\title{
KURVA PENAWARAN DAN PERMINTAAN PRODUK PERIKANAN TANGKAP PERAIRAN UMUM DARATAN DI PROPINSI SUMATERA SELATAN
}

\author{
Yesi Dewita Sari, Maulana Firdaus dan Hakim Miftakhul Huda ${ }^{1}$ \\ ${ }^{1}$ Peneliti pada Balai Besar Riset Sosial Ekonomi Kelautan dan Perikanan \\ JI. KS. Tubun Petamburan VI, Jakarta 10260 \\ Telp. 021 53650162/Fax. 02153650159
}

\begin{abstract}
ABSTRAK
Penelitian bertujuan untuk mengetahui keseimbangan kurva penawaran dan permintaan produk perikanan tangkap perairan umum daratan di Propinsi Sumatera Selatan. Penelitian dilakukan pada tahun 2007 sampai dengan 2008. Data yang digunakan adalah data primer dan sekunder. Pendugaan kurva penawaran menggunakan parameter biologi, parameter ekonomi, sedangkan pendugaan kurva permintaan menggunakan metode regresi dari beberapa variabel yang berpengaruh. Hasil penelitian menunjukkan bahwa tingkat pemanfaatan sumber daya perikanan perairan umum daratan pada kondisi MSY ditinjau dari sisi jumlah produksi adalah $85,55 \%$ dan $82,32 \%$ jika ditinjau dari jumlah effort. Kurva penawaran berbalik kebelakang pada jumlah produksi 44.004 ton dengan tingkat harga Rp. 2.350 per kg. Perpotongan kurva penawaran dan permintaan terjadi pada tingkat harga Rp. 5.200 per $\mathrm{kg}$ dan jumlah produksi 32.597 ton. Perpotongan atau keseimbangan ini terjadi pada kurva penawaran setelah berbalik ke belakang. Peningkatan produksi secara terus menerus akan menyebabkan sumberdaya perikanan perairan umum tidak lestari. Implikasi kebijakan yang dapat disarankan adalah diperlukannya kebijakan pengelolaan dengan meningkatkan produksi ikan dari usaha budidaya.
\end{abstract}

Kata kunci: Penawaran, Permintaan, Perairan Umum Daratan dan Sumatera Selatan

\section{Abstract: Supply and Demand Curve of The Inland Fishery Product in Sumatera South Province. By. Yesi Dewita Sari, Maulana Firdaus dan Hakim Miftakhul Huda'}

This reseach aimed to know equilibrium of supply and demand of both curve inland fisheries resource in South Sumatera. Biological and economical parameter are used to estimated a supply curve, and regression method is used to estimate demand curve. Result showed that exploitation rate of inland fisheries resource at MSY are $85.55 \%$ of harvest and $82,32 \%$ of effort. Backward bending supply curve happened at 44,004 ton of harvest and Rp. 2,350 of price per $\mathrm{kg}$. Supply and demand equilibrium happened at Rp. 5,200 of price per $\mathrm{kg}$ and 32,597 ton of harvest. This equilibrium happened at backward bending of supply curve. A continuing increase in production will level to unsustainable fishery production. Policy implycation could be addressed is the need for the management authority to increase fish production from aquaculture.

Keyword: Supply, Demand, Inland Fisheries, Sumatera South 


\section{PENDAHULUAN}

Sumberdaya perikanan perairan umum daratan bersifat open access dan merupakan sumberdaya yang dapat pulih. sumberdaya perikanan perairan umum meliputi sumberdaya perikanan di perairan sungai, danau, waduk dan rawa banjiran. Masingmasing sumberdaya tersebut memiliki karakteristik yang berbeda satu dengan lainnya. Menurut Welcomme (1979), habitat perairan tawar berupa sungai dan daerah banjirannya merupakan satu kesatuan fungsi yang mempunyai banyak tipe habitat yang dapat dibedakan antara musim kemarau dan musim penghujan. sumberdaya perikanan perairan umum daratan di Indonesia terbagi menjadi sungai dan rawa banjiran seluas 12 juta hektar, waduk seluas 0,05 juta hektar, dan danau seluas 1,8 juta hektar (DKP, 2006).

Provinsi Sumatera Selatan memiliki potensi sumberdaya perairan umum daratan yang cukup besar. Bagian utama perairan umum di Sumatera Selatan adalah Sungai Musi dengan sumber air yang berasal dari pegunungan Bukit Barisan dan Danau Ranau yang mengalir ke arah timur melewati Kota Palembang, dan selanjutnya bermuara di Selat Bangka. Kabupaten Ogan Komering Ilir adalah wilayah terluas di Propinsi Sumatera Selatan yang memiliki sumberdaya ini yaitu sekitar $65 \%$ dari total luas kabupaten. sumberdaya perikanan perairan umum ini merupakan penghasil ikan air tawar utama untuk memenuhi kebutuhan masyarakat di Propinsi Sumatera Selatan.

Perairan umum daratan di Propinsi Sumatera Selatan dikelola dengan adanya sistem lelang. Sistem lelang ini diatur berdasarkan Peraturan Daerah Kabupaten yang menetapkan nama dan standar harga lelang suatu objek lelang, panitia lelang, peserta lelang dan masa berlakunya. Perairan ini dihuni berbagai jenis ikan yang pada umumnya mempunyai produktivitas yang tinggi (Welcomme, 1985). Jenis ikan tersebut secara garis besar dapat dikategorikan menjadi beberapa kelompok, yakni kelompok Ikan Hitam (Black fish) seperti Gabus (Channa striata), Sepat Siam (Trichogaster pectoralis), Betok (Anabas testudineus) dan lain-lain. Kelompok yang kedua adalah Ikan Putih (White fish) seperti Lais (Cryptopterus spp), Baung (Mystus nemurus), Lampam (Puntius schwanefeldi) dan lain-lain. Pada musim kemarau kelompok ikan hitam umumnya menghuni perairan lebak yang tanahnya cekung dan dalam (lebung), sedangkan ikan putih terdapat pada perairan sungai.

Pelaksanaan sistem lelang dalam pemanfaatan sumberdaya perikanan perairan umum daratan di Sumatera Selatan telah dilakukan semenjak tahun 1630 di zaman Kerajaan Palembang Darussalam. Pada saat ini lelang dilaksanakan oleh pemerintah kabupaten dengan menetapkan harga standar objek lelang. Dengan adanya sistem lelang ini dan diaturnya harga objek lelang dikhawatirkan adanya objek lelang yang tidak laku terjual, sehingga sumberdaya perikanan di objek lelang tersebut tidak termanfaatkan. Penelitian terdahulu menunjukkan bahwa pemanfaatan sumberdaya perikanan di perairan umum daratan $80 \%$ dari kondisi Maximum Sustainable Yield. Dengan kondisi pemanfaatan yang demikian, untuk mengetahui apakah produksinya telah dapat memenuhi kebutuhan masyarakat akan protein hewani dari ikan tersebut diperlukan suatu penelitian yang dapat menggambarkan kondisi keseimbangan antara permintaan masyarakat terhadap ikan dengan produksi ikan di perairan umum daratan.

\section{METODOLOGI}

\section{Lokasi dan Waktu Penelitian}

Penelitian dilaksanakan di perairan umum daratan yang meliputi perairan sungai dan rawa banjiran di Propinsi Sumatera Selatan. Pelaksanaan penelitian berlangsung sejak tahun 2007 sampai dengan tahun 2008. 


\section{Jenis dan Sumber Data}

Data yang digunakan dalam penelitian ini adalah data sekunder dan data primer. Data sekunder yang dikumpulkan terdiri dari jumlah produksi, jumlah upaya penangkapan, jenis alat tangkap, rata-rata harga ikan, jumlah penduduk, harga barang substitusi ikan, tingkat suku bunga serta tingkat pendapatan penduduk per kapita. Data sekunder tersebut diperoleh dari Dinas Kelautan dan Perikanan Propinsi Sumatera Selatan, Dinas Perdagangan dan perindustrian, Badan Pusat Statistik dan beberapa instansi lainnya.

\section{Metode Analisis Data}

Model penawaran yang digunakan dalam penelitian ini adalah model dinamis ekonomi perikanan digambarkan melalui fungsi logistik. Stok biomas dengan fungsi logistik adalah

$$
F(x)=r x\left(1-\frac{x}{K}\right)
$$

fungsi produksi adalah

$h=q E x$ .2

Golden rule mengharuskan persamaan $\mathrm{F}(\mathrm{x})=\mathrm{h}$ dipenuhi, sehingga

$$
h=r x\left(1-\frac{x}{K}\right)
$$

Nilai biomas dapat diperoleh (Clark, 1990)

$$
x=\frac{K}{4}\left[\left(\frac{c}{p q K}+1-\frac{\delta}{r}\right)+\sqrt{\left(\frac{c}{p q K}+1-\frac{\delta}{r}\right)^{2}+\frac{8 c \delta}{p q K r}}\right] \ldots \ldots \ldots . .4
$$

Dengan mensubstitusikan nilai $\mathrm{x}$ ke dalam persamaan $\mathrm{h}$ di atas, maka kurva penawaran dapat diperoleh, dimana:h

$h=$ Produksi $/$ Production;

$r=$ Tingkat pertumbuhan intrinsik/ Intrinsic growth rate;

$\mathrm{K}=$ Daya dukung / Carrying capacity;

$q=$ Kemampuan tangkap / Catchability coeficien; $p=$ Harga ikan / Price of fish;

$c=$ Biaya penangkapan $/$ Cost of fishing;

$\delta=$ Discount rate.

Dalam persamaan kurva penawaran di atas terdiri dari parameter biologi dan parameter ekonomi. parameter biologi meliputi tingkat pertumbuhan intrinsik, daya dukung dan kemampuan tangkap. Parameter ekonomi terdiri dari harga ikan, biaya penangkapan dan discount rate. Pendugaan parameter biologi untuk sumberdaya perikanan di perairan umum Sumatera Selatan dilakukan dengan menggunakan model surplus produksi Schaefer diacu dalam Fauzi, 2004.

$$
Y_{t}=a E_{t}-b E_{t}^{2}
$$

Keterangan:

$Y_{t}$ : Jumlah produksi pada tahun $\mathrm{t} /$ Production number at $t$ year;

$E_{t}$ : Jumlah upaya penangkapan pada tahun $\mathrm{t} /$ Effort number at tyear;

$a, b$ : Koefisien yang diduga / Coefficient.

Model tersebut dapat dipecahkan menggunakan OLS dengan membuat persamaan tersebut menjadi persamaan linier seperti berikut:

$$
C P U E_{t}=a-b E_{t}
$$

Nelayan yang melakukan penangkapan ikan di perairan umum ini memiliki jumlah alat tangkap lebih dari satu (multi gears). Sehingga dalam melakukan analisis perlu dilakukan standarisasi terhadap alat tangkap yang digunakan, karena banyaknya jenis alat tangkap yang dioperasikan. Standarisasi bertujuan untuk memperoleh kemampuan tangkap yang setara dari setiap jenis alat tangkap sehingga total upaya penangkapan dapat dijumlahkan. Penentuan alat tangkap standar sangat diperlukan dalam melakukan standarisasi tersebut. Dalam penelitian ini menggunakan alat tangkap bubu sebagai alat tangkap standar. 
Dengan diketahuinya jenis alat tangkap standar, prosedur standarisasi selanjutnya adalah dengan mengetahui jumlah hasil tangkapan per trip alat tangkap atau lebih dikenal dengan catch per unit effort (CPUE) masing-masing alat tangkap. CPUE diperoleh melalui persamaan:

CPUE $_{s t}=\frac{\text { jumlah hasil tangkapan }_{s t}}{\text { jumlah upaya penangkapan }_{s t}}$
CPUE $_{t}=\frac{\text { jumlah hasil tangkapan }_{t}}{\text { jumlah upaya penangkapan }}$

St pada subscript di atas menunjukkan jenis alat tangkap standar, sedangkan subscript $i$ menunjukkan jenis alat tangkap selain alat tangkap standar. Dengan diketahuinya CPUE masing-masing alat tangkap baik alat tangkap standar maupun alat tangkap lainnya, maka dapat ditentukan indeks kemampuan tangkap (fishing power index $=F P l$ ) masing-masing jenis alat tangkap lainnya terhadap alat tangkap standar. FPI masing-masing alat tangkap dapat diperoleh dari persamaan:

$$
F P I_{i}=\frac{C P U E_{i}}{C P U E_{s t}}
$$

Setelah nilai $\mathrm{FPI}_{i}$ diperoleh, maka jumlah upaya penangkapan masing-masing alat tangkap setara dengan alat tangkap bubu dapat diperoleh menggunakan persamaan:

$$
\text { Effort }_{i \text { setara bubu }}=F P I_{i} \times \text { Effort }
$$

Parameter harga dan biaya diduga dengan menggunakan data primer yang diperoleh dari hasil wawancara dengan nelayan. Perhitungan discount rate untuk estraksi sumberdaya perikanan dengan mengacu kepada metode yang dikemukakan Clark (1990). Perhitungan discount rate dalam (Clark, 1990) diperoleh dari persamaan berikut:

$\delta_{\text {riil }}=\ln \left(1+i_{\text {riil }}\right)$
Keterangan :

$\delta_{\text {riil }}=$ Discount rate riil;

$i_{\text {riil }}=$ Interest rate riil.

Permintaan ikan dipengaruhi oleh harga ikan itu sendiri, harga barang substitusi seperti harga daging, ayam dan telur ayam, jumlah penduduk dan pendapatan. Model generik permintaan ikan yang digunakan (Koeshendrajana, 1997) adalah:

$$
D=f\left(P_{y}, P_{s t}, Y, P o p\right)
$$

dimana:

$\mathrm{D}=$ Permintaan ikan / Demand for fish;

$\mathrm{P}_{\mathrm{y}}=$ Harga ikan tersebut / Fish price;

$\mathrm{P}_{\mathrm{st}}=$ Harga barang substitusi atau komplementer / Price of substitute or complementary goods;

$\mathrm{Y}=$ Pendapatan / Income;

Pop = Populasi $/$ Population .

Dalam penelitian ini menggunakan analisis regresi linier untuk memperoleh intersep dan koefisien-koefisien. Setelah koefisien tersebut diperoleh, kemudian dilakukan analisis stepwise untuk memperoleh variabel yang lebih berpengaruh.

\section{HASIL DAN PEMBAHASAN}

\section{Pendugaan Parameter}

sumberdaya perikanan perairan umum daratan di Sumatera Selatan yang dikaji dalam penelitian ini terdiri dari sumberdaya perikanan perairan rawa dan sumberdaya perikanan perairan sungai. Jenis alat tangkap yang dioperasikan di rawa terdiri dari alat tangkap jaring insang tetap, anco, serok, rawai, pancing, sero, bubu dan alat tangkap lainnya. Jenis alat tangkap yang dioperasikan di sungai terdiri dari alat tangkap jaring insang hanyut, jaring insang tetap, anco, serok, rawai, pancing, sero, bubu dan alat tangkap lainnya.

Nelayan yang melakukan penangkapan ikan di perairan umum ini memiliki jumlah alat tangkap lebih dari satu. Pengoperasian alat tangkap tersebut ada yang menggunakan armada dan bahkan tidak menggunakan kapal/perahu sama sekali. Dalam melakukan 
analisis perlu dilakukan standarisasi terhadap alat tangkap yang digunakan, karena banyaknya jenis alat tangkap yang dioperasikan. Standarisasi bertujuan untuk memperoleh kemampuan tangkap yang setara dari setiap jenis alat tangkap sehingga total upaya penangkapan dapat dijumlahkan. Penentuan alat tangkap standar sangat diperlukan dalam melakukan standarisasi tersebut. Dalam penelitian ini menggunakan alat tangkap bubu sebagai alat tangkap standar. Rata-rata jumlah trip dari seluruh alat tangkap yang telah disetarakan bubu untuk perikanan perairan umum daratan di
Sumatera Selatan adalah 8.433.347 trip per tahun (rata-rata selama 17 tahun 1990 sampai dengan 2007). Rata-rata jumlah hasil tangkapan per tripnya adalah $5,0548 \mathrm{~kg}$ per trip.

Pendugaan parameter biologi untuk sumberdaya perikanan di perairan umum Sumatera Selatan dilakukan dengan menggunakan model surplus produksi Schaefer. Model regresi yang dihasilkan menggunakan model surplus produksi Schaefer adalah

CPUE $=0,0085-0,00000000042 E$

Tabel1. Jumlah Produksi, Effort Setara Bubu dan CPUE Ekploitasi Sumber Daya Perikanan Perairan Umum di Sumatera Selatan, 1990-2007.

Table 1. Production, Standard Effort and CPUE of the Exploitation Inland Fishery Resources in Sumatera Selatan, 1990-2007.

\begin{tabular}{rccc}
\hline $\begin{array}{c}\text { Tahun / } \\
\text { Year }\end{array}$ & $\begin{array}{c}\text { Produksi / } \\
\text { Production(ton) }\end{array}$ & $\begin{array}{c}\text { Upaya penangkapan/ } \\
\text { Effort (trip) }\end{array}$ & $\begin{array}{c}\text { CPUE } \\
\text { (kg/trip) }\end{array}$ \\
\hline 1990 & $32.949,30$ & 6.262 .951 & 5,2610 \\
1991 & $38.837,00$ & 7.424 .316 & 5,2311 \\
1992 & $39.663,10$ & 5.966 .808 & 6,6473 \\
1993 & $41.481,70$ & 6.313 .358 & 6,5705 \\
1994 & $41.979,20$ & 7.262 .632 & 5,7802 \\
1995 & $45.013,13$ & 8.274 .018 & 5,4403 \\
1996 & $41.089,10$ & 7.655 .515 & 5,3673 \\
1997 & $42.396,72$ & 5.518 .028 & 7,6833 \\
1998 & $40.402,90$ & 6.237 .971 & 6,4769 \\
1999 & $40.402,90$ & 6.304 .988 & 6,4081 \\
2000 & $41.867,87$ & 7.391 .102 & 5,6646 \\
2001 & $36.452,70$ & 8.397 .329 & 4,3410 \\
2002 & $36.938,10$ & 8.334 .822 & 4,4318 \\
2003 & $35.193,10$ & 6.857 .792 & 5,1318 \\
2004 & $34.420,50$ & 9.952 .068 & 3,4586 \\
2005 & $18.985,60$ & 16.530 .103 & 1,1485 \\
2006 & $33.788,50$ & 8.378 .491 & 4,0328 \\
2007 & $35.827,40$ & 18.737 .957 & 1,9120 \\
Rata-rata & $\mathbf{3 7 . 6 4 9 , 3 8}$ & $\mathbf{8 . 4 3 3 . 3 4 7}$ & $\mathbf{5 , 0 5 4 8}$ \\
\hline
\end{tabular}

Sumber : Dinas Kelautan dan Perikanan Kabupaten OKI, 1991-2008./

Source: Marine and Fishery Services of OKI District, 1991-2008. 


\section{Tabel 2. Parameter Biologi Sumberdaya Ikan Perairan Umum Daratan di Sumatera Selatan, 2008.}

Table 2. Biological Parameters of Inland Fishery Resources in South Sumatera, 2008.

\begin{tabular}{clr}
\hline $\begin{array}{c}\text { Koefisien/ } \\
\text { Coefisien }\end{array}$ & \multicolumn{1}{c}{ Definisi /Definition } & \multicolumn{1}{c}{$\begin{array}{c}\text { Nilai } \\
\text { Value }\end{array}$} \\
\hline$r$ & Tingkat pertumbuhan intrinsic /Intrinsic growth rate & 2,0489 \\
$q$ & Kemampuan tangkap/ Catchability coefisien & 0,0000001 \\
K & Daya dukung perairan /Carrying capacity & $85.907,45$ \\
\hline
\end{tabular}

Sumber : Data Diolah, 2008/Source: Processed Data, 2008

Variabel penjelas $\mathrm{E}$ dapat menjelaskan variabel CPUE sebesar $80,92 \%$ dan $19,08 \%$ dijelaskan oleh faktor lain yang terdapat di luar model. Nilai probabilitas untuk koefisien b sangat kecil sekali, hal ini menunjukkan bahwa variabel tersebut berpengaruh signifikan terhadap variabel CPUE dengan selang kepercayaan 99\%. Peningkatan nilai E sebesar 1 satuan akan menurunkan nilai CPUE sebesar 0,00000000042 satuan.

Dengan diketahuinya koefisien $a$ dan $b$ dari model regresi tersebut, maka parameter biologi sumberdaya perikanan perairan umum Sumatera Selatan dapat ditentukan. Parameter biologi yang dapat diduga dengan menggunakan model surplus produksi Schaefer ini hanya untuk parameter tingkat pertumbuhan intrinsik dan carrying capacity. Sedangkan untuk parameter catchability coefficient digunakan nilai yang telah diperoleh pada tahun sebelumnya. Tingkat pertumbuhan intrinsik sumberdaya perikanan di perairan umum adalah 2,0489 dan carrying capacity $85.907,45$ ton per tahun. Secara ringkas parameter biologi sumberdaya perikanan perairan umum di Sumatera Selatan disajikan pada Tabel 2.

Pendugaan parameter ekonomi juga dilakukan selain pendugaan parameter biologi seperti yang telah dilakukan. Pendugaan parameter ekonomi yaitu parameter harga, biaya tingkat suku bunga. Parameter harga diduga menggunakan data primer yang diperoleh dari hasil wawancara dengan nelayan. Jenis ikan yang diperoleh nelayan dengan melakukan operasi penangkapan ikan di perairan umum terdiri dari beberapa jenis. Jenis ikan dominan yang tertangkap antara lain Sepat Siam (Trichogaster pectoralis), Gabus (Channa striata), Lele (Clarias batrachus), Tambakan, Betok (Anabas testudineus) dan Tawes. Harga ikan ini sangat berbeda-beda tergantung tingginya permintaan dan jumlah stok ikan yang tersedia pada saat dilakukan penjualan. Harga-harga ikan tersebut berkisar antara Rp. 3.000 per $\mathrm{kg}$ sampai dengan Rp. 10.000 per $\mathrm{kg}$ dan untuk jenis lainnya dengan harga $\mathrm{Rp}$ 1.000-1.500 per kg. Ratarata harga ikan diperoleh dari total nilai penjualan ikan selama dalam satu tahun dibagi dengan jumlah produksi selama satu tahun. Dari hasil analisis usaha yang dilakukan maka rata-rata harga ikan di perairan umum Sumatera Selatan diperoleh Rp. 3.363 per kg. Parameter biaya diperoleh dari analisis usaha penangkapan ikan di perairan umum selama kurun waktu satu tahun usaha.

Interest rate yang digunakan dalam menghitung discount rate adalah real interest rate. Real interest rate diperoleh dari nominal interest rate dikurangi dengan tingkat inflasi. Data tingkat inflasi yang digunakan adalah inflasi Kota Palembang. Perhitungan discount rate yang dilakukan dalam penelitian ini adalah rata-rata interest rate dari tahun 1995 sampai dengan tahun 2005. Perhitungan interest rate real pada tahun 1998 sama dengan interest rate nominal, karena tingkat inflasi pada tahun tersebut sangat tinggi sekali, sehingga tidak dapat digunakan. Interest rate nominal, inflasi dan social discount rate disajikan pada Tabel 3. 
Tabel 3. Nominal Interest Rate, Inflasi dan Social Discount Rate di Sumatera Selatan, 1995-2005.

Table 3. Nominal Interest Rate, Inflation and Social Discount Rate in South Sumatera, 19952005.

\begin{tabular}{|c|c|c|c|}
\hline $\begin{array}{l}\text { Tahun/ } \\
\text { Year }\end{array}$ & $\begin{array}{l}\text { Suku Bunga Nominal/ } \\
\text { Nominal Interest Rate }\end{array}$ & $\begin{array}{l}\text { Laju Inflasi/ } \\
\text { Inflation Rate }\end{array}$ & $\begin{array}{l}\text { Sosial Discount Rate / } \\
\text { Social Discount Rate }\end{array}$ \\
\hline 1995 & 14,50 & 8,39 & 5,93 \\
\hline 1996 & 15,08 & 6,14 & 8,56 \\
\hline 1997 & 15,48 & 13,58 & 1,88 \\
\hline 1998 & 18,92 & 89,18 & 17,33 \\
\hline 1999 & 20,93 & $(1,01)$ & 19,84 \\
\hline 2000 & 16,32 & 8,49 & 7,54 \\
\hline 2001 & 16,44 & 15,15 & 1,28 \\
\hline 2002 & 17,47 & 12,25 & 5,09 \\
\hline 2003 & 16,87 & 5,03 & 11,19 \\
\hline 2004 & 14,65 & 8,94 & 5,55 \\
\hline 2005 & 15,45 & 11,92 & 3,47 \\
\hline
\end{tabular}

Sumber : Data Diolah, 2008/Source : Processed Data, 2008

Social discount rate diperoleh dari $\mathrm{LN}(1+$ interest rate riil). Nilai social interest rate yang digunakan untuk analisis selanjutnya adalah rata-rata social discount rate selama 11 tahun (1995-2005) tersebut yaitu 7,97\%.

\section{Kinerja Penawaran}

Jumlah biomass sumberdaya perikanan perairan umum pada kondisi maximum sustainable yield adalah 44.004,85 ton per tahun dan jumlah yang boleh ditangkap adalah 42.953,73 ton per tahun. Jumlah trip alat tangkap yang boleh dioperasikan adalah 10.244.711 trip setara bubu. Pada kondisi optimal yaitu maximum economic yield, jumlah biomas ikan adalah 56.284,26 ton, dengan jumlah yang boleh ditangkap yaitu $39.766,53$ ton per tahun.

Tingkat pemanfaatan yang telah dilakukan ditinjau dari sisi jumlah produksi adalah $85,55 \%$ dari kondisi maximum sustainable yield dan $94,68 \%$ dari kondisi maximum economic yield. Ditinjau dari jumlah upaya penangkapan, tingkat pemanfaatan yang dilakukan adalah $82,32 \%$ dari kondisi maximum sustainable yield, sedangkan pada kondisi maximum economic yield telah melebihi $100 \%$ yaitu $119,36 \%$. Upaya penangkapan yang dilakukan oleh nelayan di perairan umum daratan di Sumatera Selatan kurang efisien ditinjau dari aspek ekonomi, karena berdasarkan hasil analisis maximum economic yield jumlah effort yang diperbolehkan hanya sekitar 7 juta trip sedangkan yang telah dilakukan oleh nelayan hampir 8,5 juta trip setara bubu per tahun.

Kurva penawaran ikan pada sumberdaya perikanan perairan umum di Sumatera Selatan berbalik kebelakang pada titik MSY dengan tingkat harga Rp. 2.350 per kg. Pada tingkat harga yang berlaku saat ini yaitu Rp. 3.363, maka jumlah produksi yang 


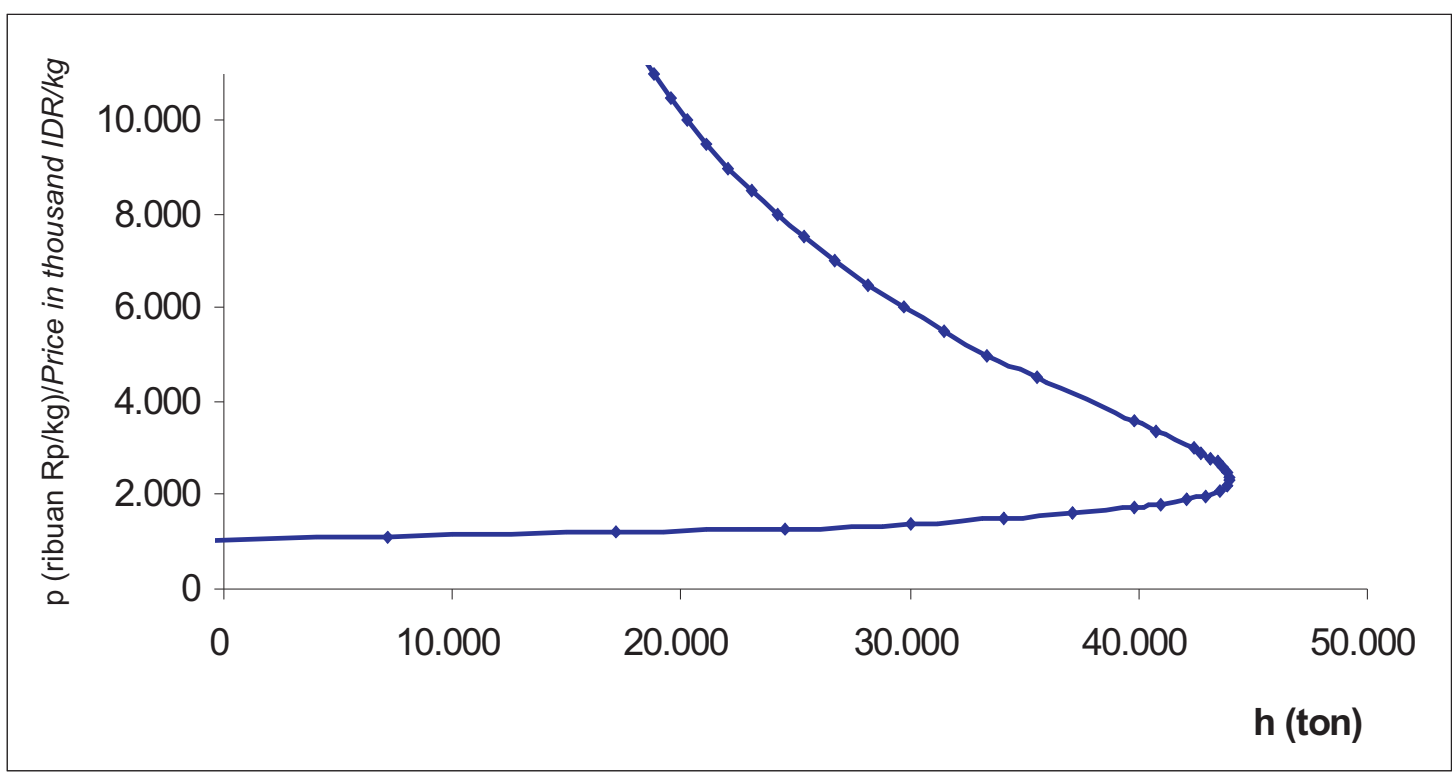

Gambar 1. Kurva Penawaran Ikan pada Sumber Daya Perikanan Perairan Umum Daratan di Sumatera Selatan, 2008.

Figure 1. Fish Supply Curve of Inland Fishery Resources in South Sumatera, 2008.

terdapat pada kurva penawaran tersebut adalah 40.788 ton. Jumlah produksi ini tidak jauh berbeda dengan rata-rata jumlah produksi aktual, hal ini menunjukkan model yang digunakan telah mendekati kondisi yang sebenarnya. Jika produksi yang dilakukan pada kondisi maximum economic yield, maka tingkat harga yang terjadi adalah Rp. 3.575 per $\mathrm{kg}$.

\section{Kinerja Kurva Permintaan}

Fungsi permintaan dinyatakan sebagai fungsi dari variabel harga atas produk itu sendiri, harga yang berhubungan dengan barang lain, jumlah populasi penduduk, pendapatan konsumen, serta variabel-variabel lain yang dianggap penting dalam penetapan estimasi permintaan. Untuk memperoleh nilai fungsi permintaan ikan di Sumatera Selatan maka dilakukan dengan cara analisis regresi permintaan konsumen sehingga ditemukan ketergantungan dari suatu variabel terhadap satu atau lebih variabel lain. Jadi teknik ini diterapkan untuk mencari nilai dari koefisienkoefisien tersebut menunjukkan pengaruh dari variabel yang menentukan permintaan ikan.

Data yang digunakan untuk analisis fungsi permintaan ikan di Sumatera Selatan meliputi produksi ikan perairan daratan di Sumatera Selatan (dalam satuan kilogram), harga rata-rata ikan perairan daratan (dalam satuan Rp/kg), jumlah penduduk Propinsi Sumatera Selatan (dalam satuan jiwa), pendapatan per kapita penduduk Propinsi Sumatera Selatan (dalam satuan Rp/kapita/tahun) dan harga barang subtitusi ikan perairan daratan yang meliputi daging, ikan asin, ayam, telur ayam dan telur itik (dalam satuan $\mathrm{Rp} / \mathrm{kg}$ ). Dalam analisis ini digunakan data runtut waktu (time series) selama 18 tahun yaitu mulai tahun 1990-2007. Adapun data yang digunakan dalam analisis regresi fungsi permintaan disajikan pada Tabel 4 berikut. 


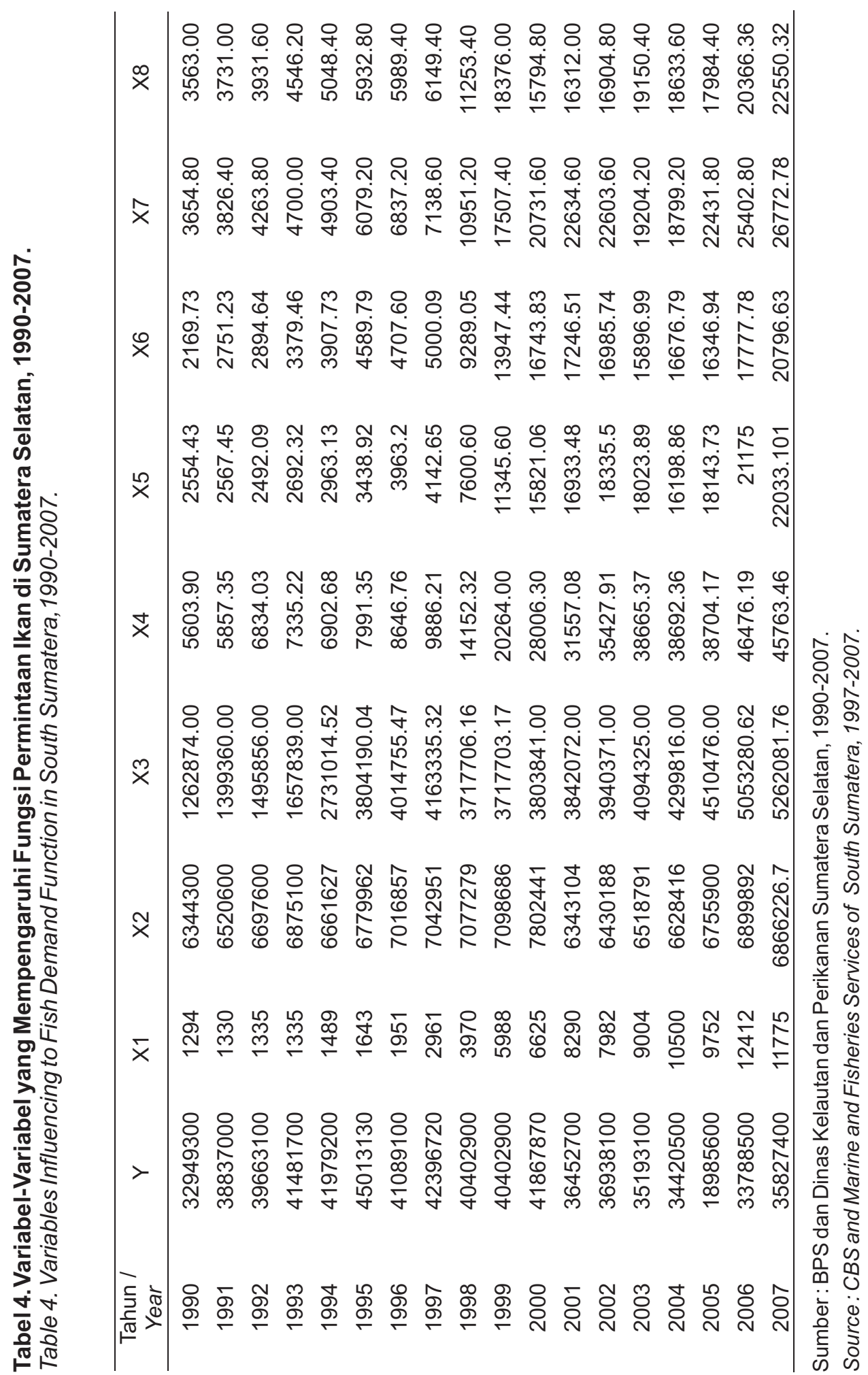


Berdasarkan analisis regresi menggunakan software minitab diperoleh fungsi permintaan ikan di Sumatera Selatan sebagai berikut :

$Y=22647907-1246 \times 1+2.32 \times 2+1.73 \times 3-$ $181 \times 4+67 \times 5+2088 \times 6-1143 \times 7-249 \times 8$

Dengan nilai $R$ squared $54,7 \%$. Nilai ini menunjukkan bahwa kurva permintaan ikan di Sumatera Selatan dapat dijelaskan sebesar $54,7 \%$ oleh seluruh variabel yang digunakan. Nilai probabilitas seluruh koefisien tidak ada yang berpengaruh signifikan pada selang kepercayaan $90 \%$. Nilai probabilitas masingmasing koefisien disajikan pada Tabel 5.

Variabel yang digunakan untuk menduga koefisien dalam kurva permintaan tidak menunjukkan pengaruh yang signifikan. Hal ini ditunjukkan oleh nilai probabilitas dari masingmasing koefisien. Variabel harga berpengaruh negatif terhadap permintaan, semakin tinggi harga ikan maka permintaan terhadap ikan tersebut akan berkurang. Variabel jumlah penduduk dan tingkat pendapatan per kapita menunjukkan nilai yang positif. Semakin tinggi jumlah penduduk dan semakin tinggi tingkat pendapatan penduduk, maka permintaan terhadap ikan semakin tinggi juga. Selain itu, harga ikan asin dan harga ayam juga berpengaruh positif terhadap permintaan ikan. Sedangkan harga daging sapi, telur ayam dan telur itik menunjukkan pengaruh yang negatif terhadap kurva permintaan ikan. Semakin tinggi harga daging sapi, telur ayam dan telur itik, maka permintaan terhadap ikan akan semakin berkurang. Dalam analisis permintaan, barang substitusi berpengaruh positif terhadap permintaan. Penelitian ini menunjukkan bahwa harga daging sapi, telur ayam dan telur itik berpengaruh negatif terhadap kurva permintaan ikan, maka dapat dikatakan ketiga produk ini bukan barang substitusi ikan di Propinsi Sumatera Selatan.

Berdasarkan fungsi permintaan ikan di atas, dalam keadaan cateris paribus, dapat diketahui bahwa kenaikan harga ikan sebesar Rp. $1 / \mathrm{kg}$ akan mengurangi permintaan ikan sebesar $1.246 \mathrm{~kg}$. Sedangkan tambahan satu jiwa penduduk akan meningkatkan permintaan ikan sebesar 2,32 kg. Kenaikan pendapatan per kapita sebesar satu rupiah akan meningkatkan permintaan ikan sebesar 1,73 $\mathrm{kg}$.

Sehubungan dengan tidak adanya satupun koefisien yang berpengaruh signifikan pada tingkat $90 \%$ maupun $85 \%$, maka selanjutnya perlu dilakukan metode stepwise

Tabel 5. Nilai Probabilitas Koefisien Kurva Permintaan Ikan di Sumatera Selatan, 2008. Table 5. Probabilitas Value of Demand Curve Coefisien in South Sumatera, 2008.

\begin{tabular}{rrr}
\hline $\begin{array}{r}\text { Koefisien/ } \\
\text { Coeficien }\end{array}$ & $\begin{array}{r}\text { Nilai Koefisien/ } \\
\text { Coeficien value }\end{array}$ & P-Value \\
\hline Konstanta & 22647907 & 0.460 \\
X1 & -1246 & 0.763 \\
X2 & 2.316 & 0.624 \\
X3 & 1.727 & 0.412 \\
X4 & -181 & 0.923 \\
X5 & 67 & 0.988 \\
X6 & 2088 & 0.339 \\
X7 & -1143 & 0.618 \\
X8 & -249 & 0.840
\end{tabular}

Sumber : Data Diolah, 2008/Source : Processed Data, 


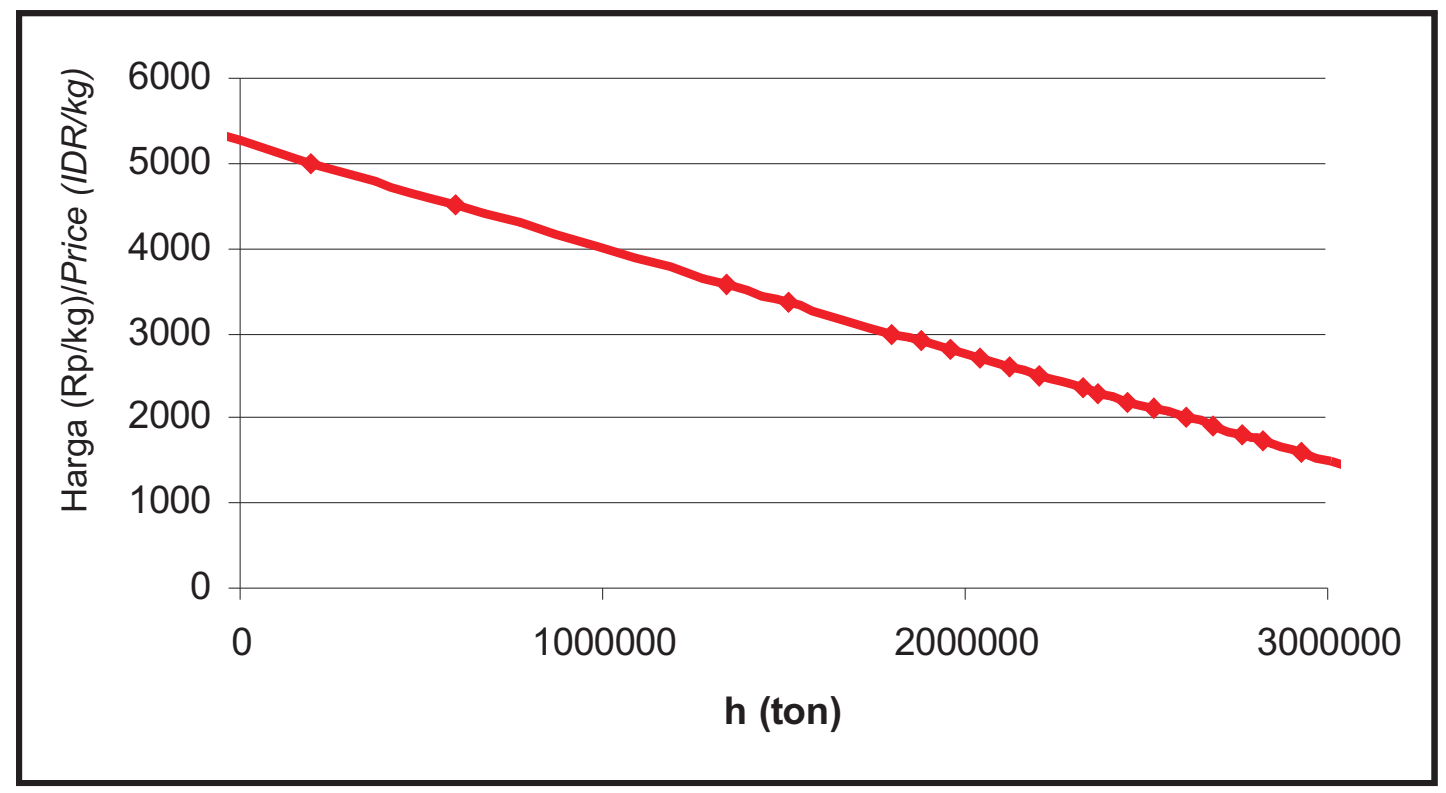

Gambar 2. Kurva Permintaan Ikan di Propinsi Sumatera Selatan, 2008.

Figure 2. Fish Demand Curve of Inland Fishery Resources in South Sumatera, 2008.

regression untuk menemukan fungsi permintaan yang signifikan. Adapun nilai koefisien setelah dilakukan metode stepwise regression pada probabilitas $90 \%$; $85 \%$ dan $80 \%$ berturut-turut adalah sebagai berikut.

$\mathrm{Y}=42096904-803 \times 1$ (probabilitas $90 \%$ )

$\mathrm{Y}=36989527-1367 \times 1+2,4 \times 3$ (probabilitas 85\%)

$\mathrm{Y}=36276229-2538 \times 1+2,1 \times 3+779 \times 6$ (probabilitas 80\%)

Adapun nilai $R$-square yang dihasilkan adalah sebesar $31,86 \%$ untuk probabilitas $90 \%$; sebesar $41,91 \%$ untuk probabilitas $85 \%$ dan $48,75 \%$ untuk probabilitas $80 \%$. Nilai adjusted $R$ square yang dihasilkan menjelaskan berapa besar pengaruh variabel bebas secara simultan terhadap fungsi permintaan. Kecilnya nilai adjusted $R$ square menunjukkan adanya variabel bebas lain yang mempengaruhi fungsi permintaan ikan di Sumatera Selatan yang belum dapat dijelaskan oleh model. Menggunakan persamaan dengan probabilitas $90 \%$, maka kurva permintaan dapat digambarkan seperti
Gambar 2. Kurva permintaan ini diperoleh dengan mensubstitusikan sejumlah harga pada persamaan yang telah diperoleh. Kurva permintaan ikan di Propinsi Sumatera Selatan mempunyai kemiringan negatif, hal ini menunjukkan bahwa semakin tinggi harga maka permintaan akan semakin menurun.

\section{Keseimbangan Kurva Penawaran dan Permintaan}

Kurva penawaran dan kurva permintaan sumberdaya perikanan perairan umum daratan di Propinsi Sumatera Selatan mengalami perpotongan pada saat kurva penawaran telah mengalami berbalik kebelakang. Perpotongan terjadi pada tingkat harga $\mathrm{Rp} 5.200$ dan jumlah produksi pada 32.597 ton. Pada perpotongan penawaran dan permintaan, kurva permintaan berbentuk garis lurus, karena jumlah produksi pada kurva permintaan jauh lebih tinggi daripada kurva penawaran. Perpotongan kurva penawaran dan permintaan sumberdaya ikan perairan umum dapat dilihat pada Gambar 3 . 


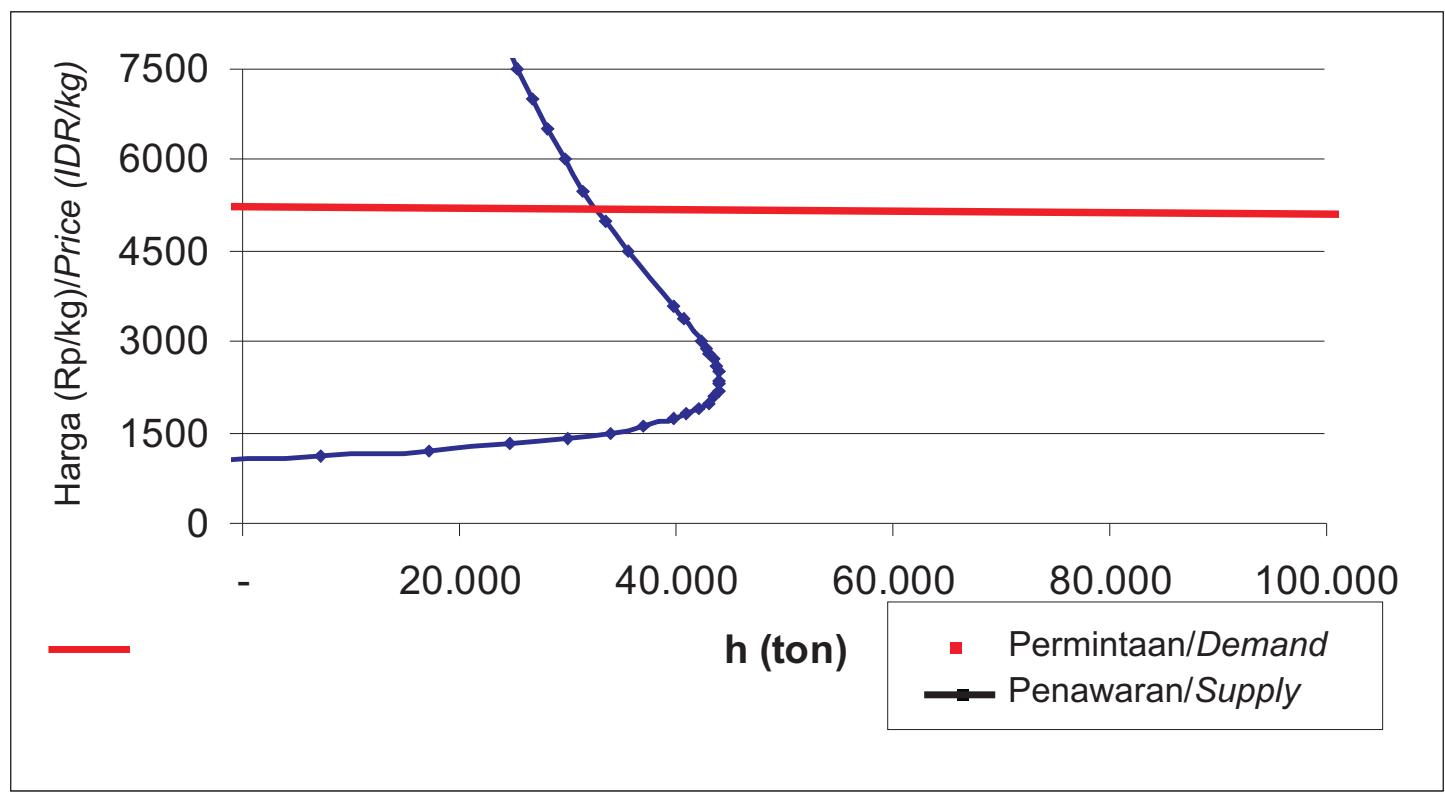

Gambar 3. Perpotongan Kurva Penawaran dan Permintaan Ikan pada Sumber Daya Perikanan Tangkap di Propinsi Sumatera Selatan, 2008.

Figure 3. Fish Supply and Demand Equilibrium of Inland Fishery Resource in South Sumatera, 2008.

Keseimbangan penawaran dan permintaan terjadi pada tingkat harga yang lebih tinggi dibandingkan rata-rata harga aktual dan tingkat harga pada kondisi maximum sustaiable yield. Hal ini menunjukkan bahwa permintaan ikan oleh masyarakat di Propinsi Sumatera Selatan cukup tinggi. Dengan tingginya permintaan ini diharapkan bahwa untuk pemenuhan kebutuhan masyarakat terhadap ikan tidak hanya diperoleh dari ikan hasil tangkapan di perairan umum. Karena dengan meningkatkan produksi ikan di perairan umum akan menyebabkan tekanan yang tinggi terhadap sumberdaya perikanan dan lambat laun akan menyebabkan kepunahan bagi spesies-spesies ikan tersebut.

Adanya perbedaan antara rata-rata harga aktual dengan harga yang terjadi pada keseimbangan penawaran dan permintaan menunjukkan bahwa ikan yang dikonsumsi tidak hanya berasal dari perikanan perairan umum daratan. Untuk mengurangi tekanan terhadap sumberdaya perikanan tangkap, sudah seharusnya diterapkan suatu pengelolaan yang mengarah kepada peningkatan usaha budidaya. Dengan budidaya ikan yang tepat, maka kebutuhan masyarakat terhadap ikan akan dapat terpenuhi, walaupun permintaan akan terus meningkat seiring dengan meningkatnya jumlah penduduk.

\section{KESIMPULAN DAN IMPLIKASI KEBIJAKAN}

\section{Kesimpulan}

Rata-rata jumlah trip alat tangkap yang beroperasi di perairan umum daratan yang diukur setara dengan bubu adalah 8.433.397 trip per tahun dengan nilai Catch per Unit Effort (CPUE) $5,05 \mathrm{~kg}$ per trip. Jumlah biomas 
sumberdaya perikanan perairan umum pada kondisi maximum sustainable yield (MSY) adalah $44.004,85$ ton per tahun dan jumlah produksi adalah 42.953,73 ton per tahun serta jumlah trip alat tangkap yang boleh dioperasikan adalah 10.244.711 trip setara bubu. Tingkat pemanfaatan yang telah dilakukan pada kondisi MSY ditinjau dari sisi jumlah produksi adalah $85,55 \%$ dan $82,32 \%$ jika ditinjau dari jumlah effort. Kurva penawaran berbalik kebelakang pada jumlah produksi 44.004 ton dengan tingkat harga Rp 2.350 per kg. Perpotongan kurva penawaran dan permintaan terjadi pada tingkat harga $\mathrm{Rp} 5.200$ per $\mathrm{kg}$ dan jumlah produksi 32.597 ton.

Perpotongan kurva penawaran dan permintaan terjadi pada tingkat harga yang lebih tinggi dari rata-rata tingkat harga aktual. Hal ini menunjukkan bahwa permintaan terhadap ikan tersebut cukup tinggi. Perpotongan atau keseimbangan ini terjadi pada kurva penawaran setelah berbalik kebelakang, peningkatan produksi secara terus menerus akan menyebabkan sumberdaya perikanan perairan umum tidak dapat dimanfaatkan secara berkelanjutan.

\section{Implikasi Kebijakan}

Oleh karena itu diperlukan suatu kebijakan pengelolaan dengan meningkatkan produksi ikan dari usaha budidaya yang dilakukan secara tepat, sehingga kebutuhan masyarakat terhadap ikan dapat terpenuhi.

\section{DAFTAR PUSTAKA}

Anonimous. 2008. Buku Tahunan Statistik Perikanan Propinsi Sumatera Selatan Tahun 1991-2008. Palembang. Sumatera Selatan.

Clark, C. 1990. Mathematical Bioeconomics, The Optimal Management of Renewable Resources. John Wiley and Sons. New York.

Departemen Kelautan dan Perikanan. 2006.Departemen Kelautan dan Perikanan dalam Angka. Jakarta.

BPS. 2008. Statistik Lingkungan Hidup I ndonesia $2006 / 2007$. http://digilib.ampl.or.id/file/pdf/AO-080$\underline{\text { 01.pdf }}$. di Akses Tangal 27 November 2008.

Fauzi, A. 2004. Ekonomi sumberdaya Alam dan Lingkungan. PT. Gramedia Pustaka Utama. Jakarta.

Koeshendrajana, S. 1997. Management Options for the Inland Fisheries Resource in South Sumatera, Indonesia. Disertasi. The University of New England. Australia. Welcomme,R.1979. Fisheries Ecology of Floodplain Rivers, Longman Group Limited, London, $317 \mathrm{p}$. 1985. FAO Fishery Resources And Environment Division. FAO Fisheries Techical Paper. No. 262. 